\title{
PENETRACIÓN IN VITRO DE VANCOMICINA EN BIOPELÍCULAS DE ESTAFILOCOCOS COAGULASA NEGATIVOS AISLADOS DE UN HOSPITAL DE LIMA-PERÚ
}

\author{
In vitro penetration of vancomicin through biofilms of coagulase negative staphylococci \\ isolated from a hospital of Lima-Peru \\ Sergio D. León ${ }^{1}$, Angela R. Rosas ${ }^{1}$, María E. Salazar ${ }^{2}$ \\ ${ }^{1}$ Facultad de Farmacia y Bioquímica. ${ }^{2}$ Instituto de Investigación en Química Biológica, Microbiología y Biotecnología "Marco Antonio \\ Garrido Malo". Facultad de Farmacia y Bioquímica. Universidad Nacional Mayor de San Marcos
}

\section{RESUMEN}

Las infecciones asociadas a bacterias formadoras de biopelículas, como estafilococos coagulasa negativos (ECoN), son difíciles de tratar debido a que en dicho estado son más resistentes a los antibióticos que en su forma planctónica, posiblemente porque no permiten la buena difusión del fármaco. El presente trabajo contribuye al conocimiento de las estrategias de resistencia por parte de estas comunidades microbianas, al plantearse como objetivos, aislar ECoN formadores de biopelículas desde catéteres venosos centrales (CVC), inducir la formación de biopelículas in vitro y evaluar la penetración de vancomicina a través de éstas. Se recolectaron 121 CVC de la Unidad de Cuidados Intensivos (UCI) del Hospital Nacional Guillermo Almenara Irigoyen. Se aislaron 46 cepas identificadas como ECoN, de las cuales el $46 \%$ fueron productoras de biopelícula según el método en agar Rojo de Congo; como controles se utilizaron Staphylococcus epidermidis ATCC 35984 (bacteria formadora de biopelículas) y Staphylococcus epidermidis ATCC 12228 (bacteria no formadora de biopelículas). La penetración de vancomicina a través de las biopelículas inducidas in vitro, fue evaluada mediante el método de Ander et al., observándose que penetró en promedio el 57,5\% de su concentración a través de las biopelículas después de seis horas de exposición, mientras que el control negativo difundió el 92,4\%. Además se evidenció que el antibiótico continuó difundiéndose hasta las 24 horas, alcanzando una penetración promedio de $82,2 \%$. El análisis estadístico demostró que no hubieron diferencias significativas entre las unidades formadoras de colonias (UFC) de las bacterias viables dentro de las biopelículas expuestas al antibiótico y sus respectivos controles.

Palabras clave: Biopelículas, estafilococos coagulasa negativos, vancomicina.

\section{SUMMARY}

Infections associated with biofilm producer bacteria, such as coagulase negative staphylococci (CoNS) are difficult to treat, because they are more resistant to antibiotics than its plactonic form, perhaps because do not allow an optimal drug diffusion. This paper aims contribute to knowledge of resistance strategies by these microbial communities, considering as objectives, isolate biofilm producer CoNS from venous catheters $(\mathrm{CVC})$, induce biofilms in vitro production and evaluate vancomycin penetration through of them. 121 CVC were collected, from Intensive Care Unit of Hospital Nacional Guillermo Almenara Irigoyen. 46 strains were identified as CoNS, being $46 \%$ of them, biofilm producers according to Congo Red agar method; Staphylococcus epidermidis ATCC 35984 (biofilm forming bacteria) and Staphylococcus epidermidis ATCC 12228 (non-biofilm forming bacteria) were used as controls. Vancomycin penetration through biofilms induced in vitro was evaluated by the Ander et al. method, observing that the antibiotic penetrated about $57,5 \%$ of its concentration through biofilms after six hours of exposure, while negative control diffused $92,4 \%$. Almost, was observed that antibiotic continued to spread until 24 hours, reaching an average penetration of $82,2 \%$. Statistical analysis showed no significant differences between counts of colonies of viable bacteria in the biofilms exposed to antibiotic and their respective controls.

Keywords: Biofilms, coagulase negative staphylococci, vancomycin.

\section{INTRODUCCIÓN}

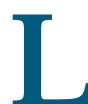

as biopelículas se forman cuando las bacterias se adhieren a superficies vivas o inertes y secretan una matriz extracelular, compuesta de proteínas y polisacáridos, que organiza y mantiene la comunidad bacteriana protegiéndola de la desecación, biocidas, cationes metálicos, radiación UV, algunos antibióticos e incluso de la acción del sistema inmune ${ }^{\mathbf{1}}$.

Las infeccionesasociadasal usodecatéteresvasculares generan alta morbilidad y mortalidad por bacteriemia y sepsis, por lo que en casos de sospecha lo que generalmente se recomienda es el retiro del catéter, sobre todo cuando se trata de CVC. Sin embargo, un alto número de pacientes requiere reinserción del dispositivo por razones como administración de terapia fluida, medicamentos, elementos sanguíneos y nutrición parenteral. Durante el intercambio existe un mayor riesgo de colonización del catéter y, por ende, de adquirir infecciones relacionadas; sin embargo, este hallazgo carece de significancia estadística ${ }^{2}$.

Los organismos en una biopelícula presentan tolerancia_variable a un amplio espectro de agentes antimicrobianos, pudiendo incluirse entre los posibles mecanismos de resistencia el retraso en la penetración del fármaco, alteración en el porcentaje de crecimiento de los organismos de dicha comunidad y los cambios fisiológicos asociados al modo de crecimiento que se da en las biopelículas ${ }^{3}$. 


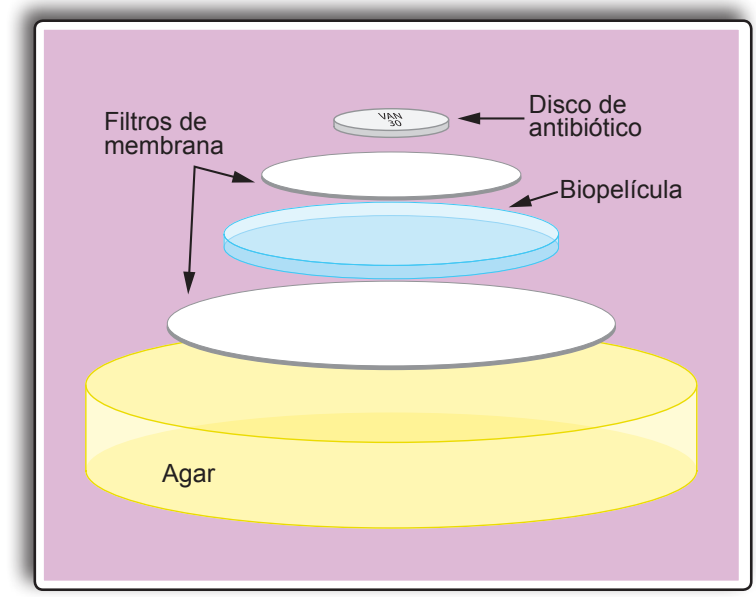

Figura 1. Esquema "sándwich".

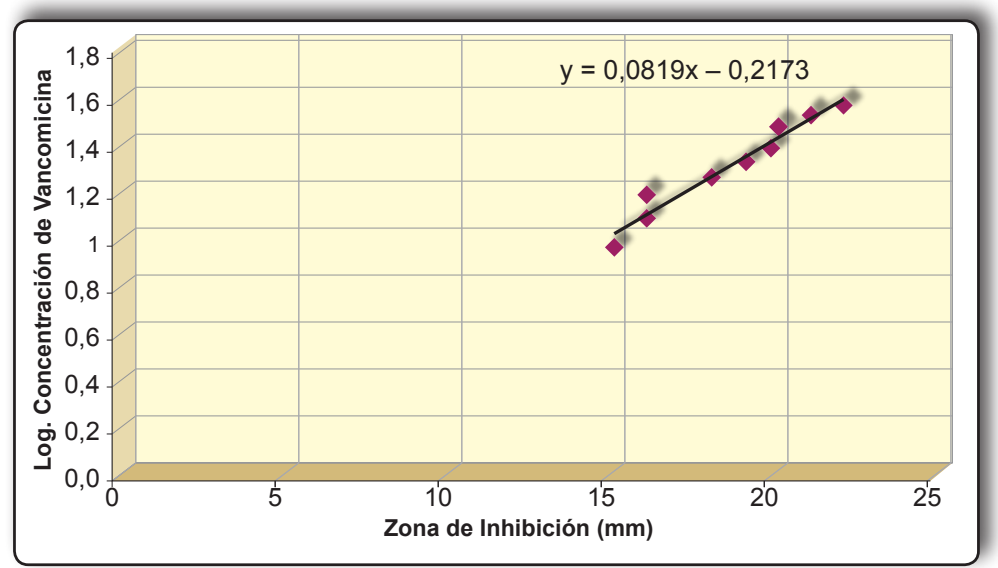

Figura 2. Relación entre las concentraciones del estándar de vancomicina y la zona de inhibición frente a Staphylococcus aureus ATCC 25923.

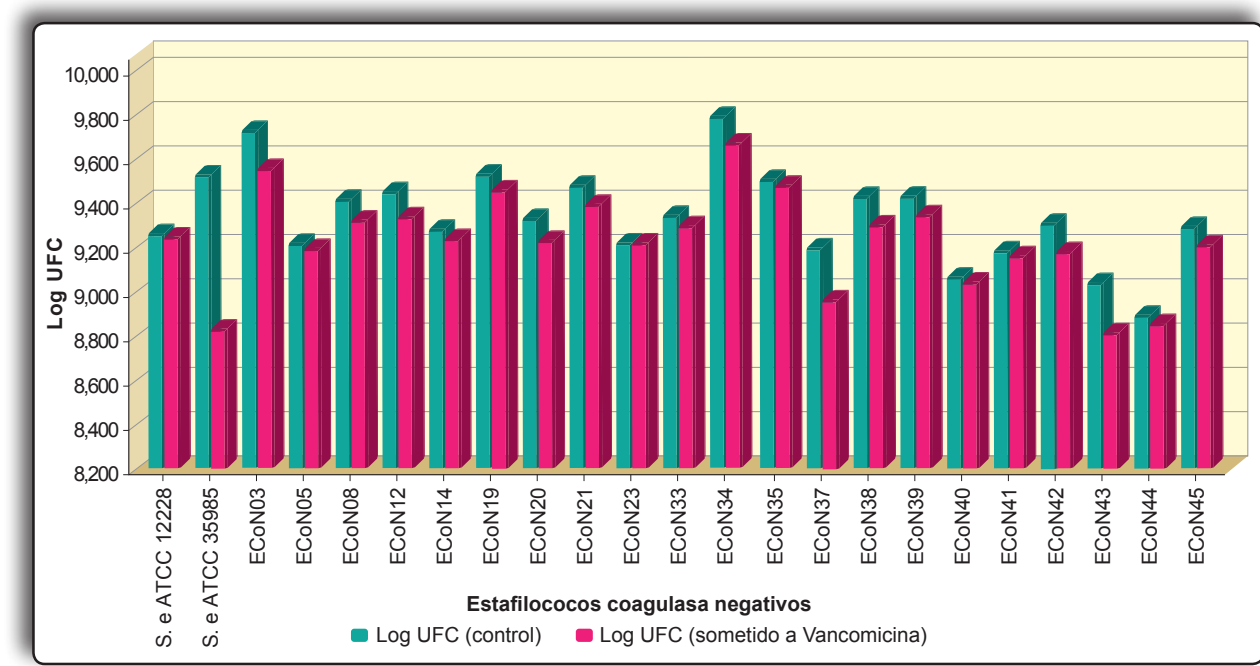

Figura 3. Resultados de la enumeración bacteriana de las biopelículas a las 6 horas.

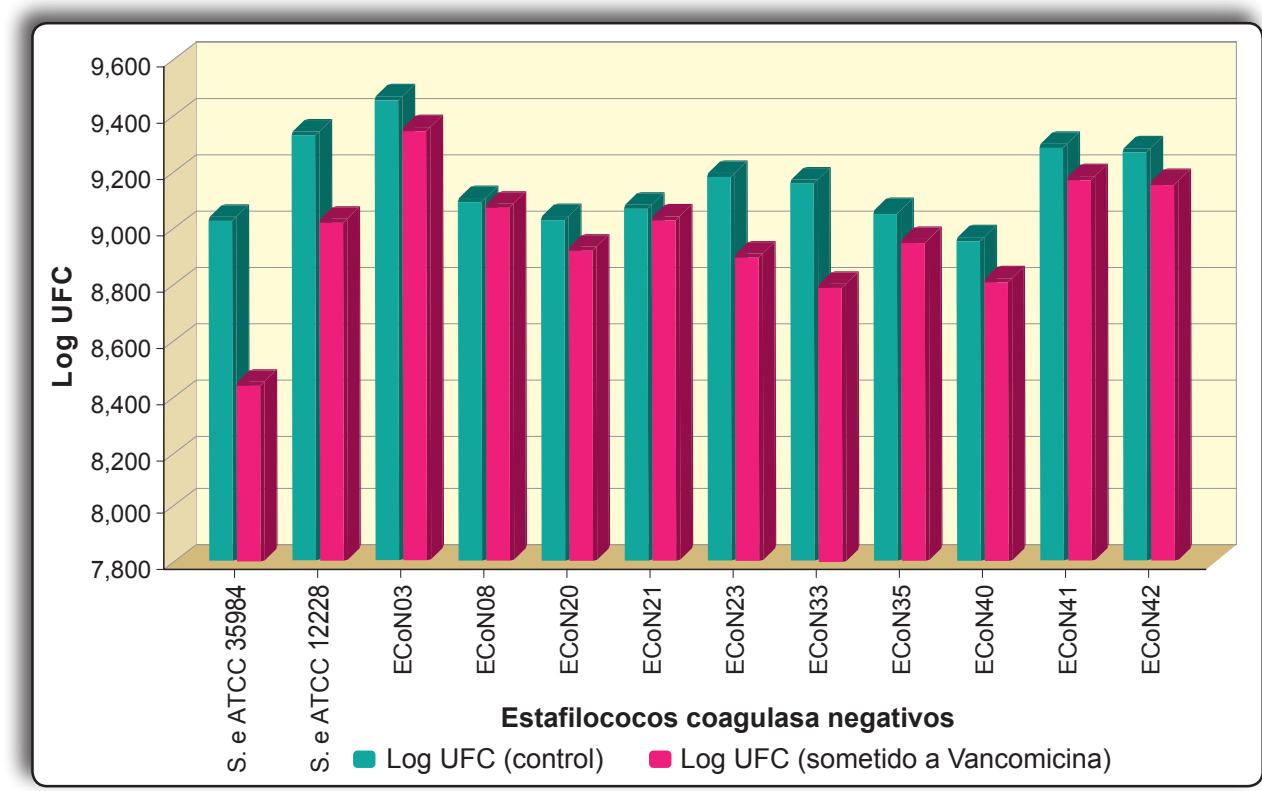

Figura 4. Resultados de la enumeración bacteriana de las biopelículas a las 24 horas.
Los

estafilococos coagulasa negativos (ECoN), son frecuentemente encontrados en la flora normal de la piel humana y membranas mucosas. La mayoría de las infecciones debidas a estos microorganismos son nosocomiales y asociadas a catéteres, lo que posiblemente haya propiciado el incremento de resistencia frente a antibióticos, la cualesfavorecidaporsucapacidad de producción de biopelículas además de otros factores de virulencia de la bacteria. Staphylococcus epidermidis, por ejemplo, es reconocido como un importante patógeno oportunista, la causa más común de infecciones asociadas al uso de dispositivos médicos, y junto con $S$. aureus, se ubica entre los primeros agentes causales de las infecciones nosocomiales. A pesar de la amplia resistencia a meticilina y otros antibacterianos, el $80 \%$ de catéteres infectados con $S$. epidermidis se tratan con antibióticos como vancomicina, sin remover el catéter. Sin embargo, parece existir resistencia intermedia a este medicamento, que al igual que otros, sufre una significativa disminución en su actividad debidoa las biopelículas formadas por estafilococos ${ }^{4}$.

Las biopelículas causan un porcentaje elevado de infecciones humanas. Las infecciones nosocomiales son la cuarta causa de muerte en Estados Unidos, con dos 
millones de casos anuales (aproximadamente 10\% de pacientes hospitalizados) lo que equivale a casi cinco billones de dólares en costo médico por año ${ }^{5}$. Desde el 2005, el Perú viene realizando la vigilancia epidemiológica de las infecciones intrahospitalarias, la cual tiene como característica de ser activa, selectiva y focalizada lo que limita el conocimiento de la magnitud del problema en el país ${ }^{6}$.

Con el fin de contribuir al conocimiento de las estrategias utilizadas por estas comunidades microbianas asociadas a infecciones intra y extrahospitalarias, el presente trabajo tuvo como objetivo evaluar la acción bactericida de vancomicina sobre biopelículas de ECoN, para lo cual se determinó la sensibilidad de las cepas al antibiótico y se indujo la formación de biopelículas in vitro para estudiar la penetración del fármaco en ellas y su acción antimicrobiana.

\section{MATERIAL Y MÉTODOS}

Se planteó un estudio experimental, caso control, que fue realizado en el Instituto de Investigación en Química Biológica, Microbiología y Biotecnología “Marco A. Garrido Malo" de la Facultad de Farmacia y Bioquímica de la UNMSM.

Muestras: 121 catéteres venosos centrales (CVC) procedentes de la Unidad de Cuidados Intensivos (UCI) del Hospital Nacional Guillermo Almenara Irigoyen, que se retiraron de los pacientes por indicación del médico y se recolectaron en tubos estériles de 13 x $100 \mathrm{~mm}$.

Procesamiento de las muestras: Las muestras fueron procesadas según la técnica establecida por Murga et al. ${ }^{7}$, que consistió en sumergir la punta del CVC, en hipoclorito de sodio al o,5\% por 10 minutos y luego en solución de tiosulfato

Tabla 1. Penetración de vancomicina a través de las biopelículas.

\begin{tabular}{|c|c|c|c|c|c|c|}
\hline \multirow[b]{2}{*}{$\begin{array}{l}\text { Cepa } \\
\text { ECoN }\end{array}$} & \multicolumn{3}{|c|}{ Prueba a las 6 horas } & \multicolumn{3}{|c|}{ Prueba a las 24 horas } \\
\hline & $\begin{array}{l}\text { Halo de } \\
\text { inhibición } \\
\text { (mm) }\end{array}$ & 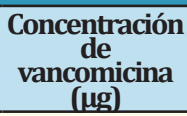 & $\begin{array}{c}\text { Vancomicina } \\
\text { difundida a } \\
\text { través de la } \\
\text { biopelícula }(\%)\end{array}$ & $\begin{array}{c}\text { Halo de } \\
\text { inhibición } \\
\text { (mm) }\end{array}$ & $\begin{array}{c}\text { Concentración } \\
\text { de } \\
\text { vancomicina } \\
(\mu g)\end{array}$ & $\begin{array}{l}\text { Vancomicina } \\
\text { difundida a } \\
\text { través de la } \\
\text { biopelícula }(\%)\end{array}$ \\
\hline Control (+) & 17 & 14,96 & 50,13 & 12 & 5,83 & 80,57 \\
\hline Control (-) & 7 & 2,27 & 92,43 & 7 & 2,27 & 92,43 \\
\hline ECoN 03 & 15 & 10,26 & 65,80 & 11,5 & 5,3 & 82,33 \\
\hline ECoN 05 & 16 & 12,39 & 58,70 & 11 & 4,83 & 83,90 \\
\hline ECoN 08 & 16 & 12,39 & 58,70 & 11,5 & 5,3 & 82,33 \\
\hline ECoN 12 & 15 & 10,26 & 65,80 & 11,5 & 5,3 & 82,33 \\
\hline ECoN 14 & 16 & 12,39 & 58,70 & 11 & 4,83 & 83,90 \\
\hline ECoN 19 & 16 & 12,39 & 58,70 & 10,5 & 4,39 & 85,37 \\
\hline ECoN 20 & 16 & 12,39 & 58,70 & 11 & 4,83 & 83,90 \\
\hline ECoN 21 & 17 & 14,96 & 50,13 & 11 & 4,83 & 83,90 \\
\hline ECoN 23 & 16 & 12,39 & 58,70 & 12 & 5,83 & 80,57 \\
\hline ECoN 33 & 15 & 10,26 & 65,80 & 11,5 & 5,3 & 82,33 \\
\hline ECoN 34 & 15 & 10,26 & 65,80 & 11 & 4,83 & 83,90 \\
\hline ECoN 35 & 16 & 12,39 & 58,70 & 13 & 7,04 & 76,53 \\
\hline ECoN 37 & 17 & 14,96 & 50,13 & 11,5 & 5,3 & 82,33 \\
\hline ECoN 38 & 16 & 12,39 & 58,70 & 10,5 & 4,39 & 85,37 \\
\hline ECoN 39 & 16 & 12,39 & 58,70 & 10,5 & 4,39 & 85,37 \\
\hline ECoN 40 & 17 & 14,96 & 50,13 & 12 & 5,83 & 80,57 \\
\hline ECoN 41 & 16 & 12,39 & 58,70 & 11 & 4,83 & 83,90 \\
\hline ECoN 42 & 18 & 18,07 & 39,77 & 12 & 5,83 & 80,57 \\
\hline ECoN 43 & 17 & 14,96 & 50,13 & 13 & 7,04 & 76,53 \\
\hline ECoN 44 & 16 & 12,39 & 58,70 & 13 & 7,04 & 76,53 \\
\hline ECoN 45 & 16 & 12,39 & 58,70 & 11 & 4,83 & 83,90 \\
\hline Promedio & & & 57,5 & & & 82,2 \\
\hline
\end{tabular}

de sodio o,12M por 1 minuto. Seguidamente el catéter se cortó transversalmente y se colocó en un tubo con buffer fosfato salino (PBS, de sus siglas en inglés), el que se sonicó por 15 minutos. La suspensión se sembró en caldo nutritivo y en agar TSA e incubó a $35^{\circ} \mathrm{C}$ por 24 horas.

Identificación microbiológica de estafilococos coagulasa negativos: La identificación inicial de las bacterias se realizó según las especificaciones del Manual de Procedimientos de Laboratorio de Infecciones Intrahospitalarias del INS ${ }^{\mathbf{8}}$, que consiste en someter la colonia aislada en TSA a las siguientes pruebas: observación de la morfología celular, fermentación en manitol, catalasa, DNAsa, coagulasa.

Selección de cepas ECoN formadoras de biopelículas: Se utilizaron Staphylococcus epidermidis ATCC 35984 como control positivo y Staphylococcus epidermidis ATCC 12228 como control negativo. Se procedió según dos técnicas:

La de Freeman et al. ${ }^{9}$, que consistió en sembrar la cepa estudiada en agar rojo de congo e incubarlo a $35^{\circ} \mathrm{C}$ por 48 horas; las bacterias productoras de biopelículas formaron colonias negras.

La de Christensen et al. ${ }^{10}$, en la que se inoculó la cepa en estudio en un tubo de vidrio conteniendo TSB y se incubó a $35^{\circ} \mathrm{C}$ por 48 horas. Luego se separó el cultivo líquido del tubo y se lavó con PBS dos veces, para después teñir con safranina al o,25\%. La película coloreada formada sobre la superficie del tubo se consideró positiva.

Selección de cepas ECoN formadoras de biopelículas sensibles a lavancomicina: Se seleccionaron las cepas ECoN de acuerdo a su sensibilidad antimicrobiana determinada por el método de difusión en disco (Kirby-bauer) recomendado por el INS ${ }^{11}$ el cual consistió en inocular y extender con un hisopo estéril, sobre una superficie seca de agar Mueller Hinton (AMH) el cultivo de las cepas aisladas ajustado a la escala 0,5 de McFarland, para luego colocar encima los discos de vancomicina. Las placas se incubaron a $35^{\circ} \mathrm{C}$ por 24 horas. La interpretación de los resultados se realizó de acuerdo a tablas referenciales ${ }^{\mathbf{1 1}}$.

Inducción a la formación in vitro de biopelículas de ECoN: Se realizó mediante la técnica de Anderl et al. ${ }^{12}$. Un cultivo de 24 horas se diluyó en PBS hasta una densidad óptica de 0,2 a $600 \mathrm{~nm}$. Se inocularon $40 \mu \mathrm{L}$ de la dilución sobre una membrana de filtro estéril (25 mm de diámetro por 0,2 $\mu \mathrm{m}$ de poro) que estaba a su vez colocada sobre agar TSA. Luego las placas se invirtieron y se incubaron a $35^{\circ} \mathrm{C}$ por 48 horas. Cada 12 horas la membrana fue transferida a una placa nueva de TSA. 
Ensayo de penetración del antibiótico vancomicina: Se hizo mediante la técnica de Anderl et al. ${ }^{12,13}$. Sobre la superficie de la biopelícula de ECoN inducida en la membrana, se colocó una segunda membrana pequeña (de $13 \mathrm{~mm}$ de diámetro y 0,2 $\mu$ m de poro), encima de la cual se puso un disco de vancomicina humedecido con $24 \mathrm{~mL}$ de caldo TSB. Este "sándwich", que se presenta en la figura 1, de la biopelícula de ECoN fue transferido a una placa con agar TSA a temperatura ambiente.

Después de cada tiempo específico (6 horas y 24 horas), los discos de vancomicina se transfirieron del TSA a AMH previamente inoculado con $100 \mu \mathrm{L}$ de un cultivo de Staphylococcus aureus ATCC 25923 ajustado a la escala 0,5 de McFarland. La placa se incubó a $35^{\circ} \mathrm{C}$ por 24 horas y luego se midió la zona de inhibición de crecimiento.

Para determinar la concentración del antibiótico que difundió de los discos hacia las biopelículas, se realizaron una serie de diluciones de vancomicina y se cargaron sobre discos estériles para hacer un antibiograma con la cepa $S$. aureus ATCC 25923, con la finalidad de obtener una relación estándar entre las concentraciones de vancomicina y las zonas de inhibición obtenidas.

Enumeración bacteriana de la biopelícula de ECoN sometida al antibiótico vancomicina: Se realizó mediante la técnica de Anderl et al. ${ }^{12}$ Se transfirió el sándwich de la biopelícula sometido a la prueba de penetración del antibiótico, con su respectivo control (que no fueron sometidas), a tubos con PBS y luego llevados a un vortex por 2 minutos. Después se realizaron diluciones en PBS hasta $10^{-7}$ y se sembró por el método de incorporación.

Análisis estadístico de la enumeración bacteriana de la biopelícula de ECoN sometido al antibiótico vancomicina: Para analizar si existía diferencias entre las UFC de las biopelículas inducidas in vitro que fueron sometidas a la prueba de penetración de la vancomicina (grupo experimental) y las UFC aquellas no sometidas a dicha prueba (grupo control), se utilizó el test de Fisher con un nivel de significancia de $a=0,05$ de dos colas, que determinó la relación entre dos variables categóricas.

\section{RESULTADOS}

Se aislaron 72 cepas de las cuales 64\% (46/72) fueron estafilococos coagulasa negativos. En cuanto a la sensibilidad a vancomicina se encontró que el 100\% de las cepas de ECoN eran sensibles.

Según la técnica de Freeman et al. ${ }^{9}$, se encontró que $46 \%(21 / 46)$ de los ECoN desarrollaron colonias negras en el agar Rojo de Congo, característica de los microorganismos con capacidad de formar biopelículas. Según la técnica de Christensen et al. ${ }^{10}$, se halló que $37 \%$ (17/46) de los ECoN desarrollaron una fina película blanquecina, adherida a la pared de los tubos, que se colorea de rojo al agregar safranina, característica de los microorganismos con capacidad de formar biopelículas.

La concentración de antibiótico que penetró a través de la biopelículas se determinó indirectamente midiendo los halos de inhibición de los discos con diluciones de vancomicina en el AMH sembrado con $S$. aureus ATCC 25923 (figura 2). Los resultados mostraron que a las 6 horas de someterse a la prueba de penetración hubo una lenta difusión del antibiótico a través de la biopelícula, sólo 57,5\% pudo difundir comparada con la difusión de la cepa no formadora de biopelícula; mientras que el promedio de difusión después de 24 horas en las cepas formadoras de biopelículas fue 82,2\% (tabla 1 ).

Los resultados de la enumeración bacteriana de las biopelículas producidas por ECoN sometidos a la acción de vancomicina se muestran en las figuras 3 y 4.

\section{DISCUSIÓN}

De los dos métodos utilizados para evaluar la formación de biopelículas por ECoN, se encontró que el método en agar Rojo de Congo fue más rápido, sensible, reproducible y tiene la ventaja de recuperar las colonias viables. El método en tubo de Christensen et al. ${ }^{10}$, podría tener como restricción la sensibilidad debido a que no puede detectar capas delgadas de exopolisacáridos. Esto fue confirmado con el presente trabajo, en el que de 46 cepas aisladas, 21 dieron positivo al método del Rojo de Congo y sólo 17 cepas al método en tubo.

Se logró inducir, en todas las cepas de ECoN con capacidad de hacerlo, la formación de biopelículas in vitro sobre filtros de membrana; sin embargo, seobservó quealgunas cepas, al ser repicadas constantemente en medios de cultivo, aparentemente perdían dicha facultad. Otros trabajos, como el de Christensen et al. ${ }^{10}$, evidenciaron esto al demostrar que dos cepas hijas de $S$. epidermidis ATCC 35984, queexhibían la misma susceptibilidad antimicrobiana y reacciones bioquímicas, eran genéticamente idénticas, pero se diferenciaban en la capacidad de producir biopelículas. Del mismo modo Baselga et al. ${ }^{\mathbf{1 4}}$, observaron que cepas de $S$. aureus, aisladas de leche de bovino con mastitis, perdían rápidamente la capacidad de producir exopolisacáridos en sus cultivos in vitro, lo que sugiere que un pequeño número de cepas no formadoras de biopelículas podrían producirse de una población de bacterias productoras, pudiendo tener estas variantes un crecimiento acelerado comparadas con las formadoras de biopelículas.

En la prueba de penetración se observó que hubo lenta difusión de vancomicina en las biopelículas $(57,5 \%)$ comparada con el control negativo, en el que, al cabo de 6 horas ya había difundido 92,4\% del antibiótico; sin embargo, a las 24 horas el antibiótico llegó a difundirse hasta en $82,2 \%$ en las cepas formadoras de biopelículas. Estos resultados no son muy diferentes a los reportados antes por otros investigadores. Dunne et al. ${ }^{15}$, usaron una cámara de diálisis para evaluar la penetración de vancomicina a través de la biopelícula de $S$. epidermidis ATCC 35984 y observaron que después de 24 horas sólo se difundió 30\% del antibiótico. Ortíz-Pérez et al. ${ }^{16}$, demostraron que las biopelículas de micobacterias presentaron resistencia frente a los antibióticos que son empleados habitualmente en las infecciones que causan, encontrando diferencias en la penetración con una importante disminución de la permeabilidad frente a ciprofloxacino. Estos hallazgos indicarían que en un sistema de biopelícula la difusión es limitada, ya que el flujo es reducido y la distancia de difusión se incrementa a medida que se desarrolla la biopelícula.

El análisis estadístico reveló que no existen diferencias significativas entre las biopelículas sometidas a la prueba de penetración de vancomicina y su grupo control en ambos ensayos (6 horas y 24 horas). Estos resultados podrían demostrar que la acción de la vancomicina ha sido 
alterada al no reducir la población bacteriana dentro de la biopelícula, lo que posiblemente se deba a los bajos niveles de concentración dentro de ésta por la lenta difusión del antibiótico observada; este hallazgo es similar al obtenido por Evans et al. 17 al desarrollar biopelículas de $S$. epidermidis sobre biomateriales de silicona in vitro, no encontrando diferencia significativa después de diez días de tratamiento.

Qu et al. ${ }^{18}$, demostraron que la resistencia de los ECoN a múltiples antibióticos, inicialmente es similar cuando la bacteria está en su forma plactónica o cuando está en la fase de adherencia temprana, y luego se incrementa a medida que la adherencia se desarrolla. Del mismo modo, Pinheiro et al. ${ }^{19}$, encontraron que 51 (47,7\%) cepas de $S$. epidermidis crecían en agar conteniendo $4 \mu \mathrm{g} /$ $\mathrm{mL}$ de vancomicina, mientras que tres $(2,8 \%)$ aislados crecieron en agar con $6 \mu \mathrm{g} / \mathrm{mL}$ del antibiótico; al evaluar la presencia de los genes van $A$ y van $B$ de resistencia a dichoantibiótico, todas las cepas dieron negativo. Estos resultados demostrarían que estos sistemas bacterianos podrían ser responsables de un decrecimiento significativo de la eficacia de algunos antibióticos, mientras que otrossonmínimamenteafectados. Esconocidoquelavancomicina es un antibiótico de elección contra infecciones causadas por estafilococos meticilinoresistentes; sin embargo, los glucopéptidos podrían fallar en el tratamiento de infecciones por implantes o dispositivos médicos, debido a que los microorganismos podrían estar atrapados dentro de una matriz de exopolisacáridos.

\section{CONCLUSIONES}

Se identificaron $64 \%$ de cepas ECoN, provenientes de 72 aisladas de 121 CVC provenientes de UCI, de las cuales $46 \%$ eran formadoras de biopelículas y todas fueron sensibles a vancomicina.

Se logró inducir la formación de biopelículas en el $100 \%$ de las cepas productoras y al evaluar la penetración de la vancomicina, ésta difundió un promedio de $57,5 \%$ de su concentración a través de las biopelículas in vitro después de seis horas de exposición, siendo lenta comparada con la observada en el control negativo (92,4\%). Sin embargo la difusión del antibiótico continuó hasta las 24 horas alcanzando una penetración promedio de $82,2 \%$.

No hubieron diferencias significativas entre los recuentos de bacterias viables en las biopelículas expuestas al antibiótico a las 6 y 24 horas y sus respectivos controles.

\section{REFERENCIAS BIBLIOGRÁFICAS}

1. Flemming HC, Wingender J. The biofilm matrix. Nat Rev Microbiol. 2010; 8: 623-33.

2. Chin BS, Han SH, Lee HS, Jeong SJ, Choi H, Kim CO, et al. Risk factors for recurrent catheter-related infections after catheterrelated bloodstream infections. Int J Infect Dis. 2010; 14(1): e16-21.

3. Donlan RM. Biofilm elimination on intravascular catheters: important considerations for the infectious disease practitioner. Clin Infect Dis. 2011; 52 (8): 1038-45.

4. Otto M. Staphylococcus epidermidis--the 'accidental' pathogen. Nat Rev Microbiol. 2009; 7(8): 555-67.

5. Wenzel RP. Health care-associated infections: major issues in the early years of the 21st century. Clin Infect Dis. 2007; 45 (Suppl. 1): S85-8

6. Garro G, Quispe Z. Protocolo: Estudio prevalencia de infecciones intrahospitalarias. Ministerio de Salud, Dirección General de Epidemiología, Perú. Lima; 2014.

7. Murga R, Miller JM, Donlan RM. Biofilm formation by gram-negative bacteria on central venous catheter connectors: effect of conditioning films in a laboratory model. J Clin Microbiol. 2001; 39(6): 2294-7.

8. Sacsaquispe R, Ventura G. Manual de Procedimientos Bacteriológicos en Infecciones Intrahospitalarias. Serie de Norma Técnica $\mathrm{N}^{\circ}$ 28. Lima: MINSA-INS, 2001.

9. Freeman DJ, Falkiner FR, Keane CT. New method for detecting slime production by coagulasa negative staphylococci. J Clin Pathol. 1989; 42(8): 872-4.

10. Christensen GD, Baddour LM, Simpson WA. Phenotypic variation of Staphylococcus epidermidis slime production in vitro and in vivo. Infect Immun. 1987; 55(12): 2870-7

11. Sacsaquispe R, Velásquez J. Manual de procedimientos para la prueba de sensibilidad antimicrobiana por el método de Disco Difusión. Seriede Norma Técnica N³0. Lima: MINSA-INS; 2002.

12. Anderl JN, Franklin MJ, Stewart P. Role of antibiotic penetration limitation in Klebsiella pneumoniae biofilm resistance to ampicillin and ciprofloxacin. Antimicrob Agents Chemother. 2000; 44(7): 1818-24

13. Zheng Z, Stewart PS. Penetration of rifampin through Staphylococcus epidermidis Biofilms. Antimicrob Agents Chemother. 2002; 46(3): 900-3.

14. Baselga R, Albizu I, De la Cruz M, Del Cacho E, Barberan M, Amorena B. Phase variation of slime production in Staphylococcus aureus: implications in colonization and virulence. Infect Immun. 1993; 61(11): 4857-62.

15. Dunne WM Jr. Bacterial adhesion: seen any good biofilm lately?. Clin Microbiol Rev. 2002; 15(2): 155-66.

16. Ortíz-Pérez A, Martín-de-Hijas N, Alonso-Rodríguez N, Molina-Manso D, Fernández-Roblas R, Esteban J. Importanceof antibiotic penetration in the antimicrobial resistance of biofilm formed by non-pigmented rapidly growing mycobacteria against amikacin, ciprofloxacin and clarithromycin. Enferm Infecc Microbiol Clin. 2011; 29(2): 79-84.

17. Evans RC, Holmes CJ. Effect of vancomycin hydrochloride on Staphylococcus epidermidis biofilm associated with silicone elastomer. Antimicrob Agents Chemother. 1987; 31(6): 889-94.

18. Qu Y, Daley AJ, Istivan TS, Garland SM, Deighton MA. Antibiotic susceptibility of coagulase-negative staphylococci isolated from very low birth weight babies: comprehensive comparisons of bacteria at different stages of biofilm formation. Ann Clin Microbiol Antimicrob [Internet]. 2010 [Citado 16 febrero 2016]; 9: 16. Disponible en: https://www.ncbi.nlm.nih. gov/pmc/articles/PMC2902406/pdf/1476-0711-9-16.pdf

19. Pinheiro L, Brito CI, Pereira VC, Oliveira A, Camargo CH, Cunha M. Reduced susceptibility to vancomycin and biofilm formation in methicillin-resistant Staphylococcus epidermidis isolated from blood cultures. Mem Inst Oswaldo Cruz. 2014; 109(7): 871-8.

Manuscrito recibido el: 02/05/2016

Aceptado para su publicación el: 19/o9/2016

\section{Correspondencia:}

Nombre: María Elena Salazar Salvatierra

Dirección: Jr. Puno 1002 - Lima

e-mail: msalazars@unmsm.edu.pe 